\title{
$\operatorname{CONF}=840902--6$
}

By acceptance of this articl? the publisher or recipient acknowledges the U.S. Government's right to retein nonexclusive, royelty-tree license in and to ariy copyright covering the article. CONF $-340902--6$

DE85 001.132

RECENT PROGRESS AMD DEVELOPMENTS IN LWR-PV CALCULATIONAL METHODOLOGY*

R. E. Maerker, B. L. Broadhead and M. L. Williams ${ }^{\dagger}$

Oak Ridge National Laboratory

Dak Ridge, TN 37831

\begin{abstract}
New and improved techniques for calculating beltiine surveillance activities and pressure vessel fluences with reduced uncertainties have recently been developed. These techniques involve the combining of monitored incore power data with diffusion theory calculated pin-bypin data to yield absolute source distributions in $R-\theta$ and $R-Z$ geometries suitable for discrete ordinate transport calculations. Effects of finite core height, whenever necessary, can be considered by the use of a threedimensional fluence rate synthesis procedure. The effects of a time-dependent spatial source distribution may be readily evaluated by applying the concept of the adjoint function, and simplifying the procedure to such a degree that oniy one forward and one adjoint calculation are required to yield all the dosimeter activities for all beltline surveillance locations at once. The addition of several more adjoint caiculations using various group fluence rates as responses is all that is needed to determine all the pressure vesse? group fluences for all beltline locations for any arbitrary source distribution.
\end{abstract}

\footnotetext{
*Work performed for the Electric Power Research Institute under research project 1399-1 with the Dak Ridge National Laboratory and under Interagency Agreenents 40-551-75 and 40-552-75, NRC FIN No. BU415, and with the Mariin Marietta Energy Systems, Inc. under contract DE-AC05-840R21400 with the U.S. Defartment of Energy. tLol isiana State University, Baton Rouge, LA 70803.
} 


\section{RECENT PROGRESS IN LWR-PV CALCULATIONAL METHODOLOGY}

\section{INTRODUCTION}

In enlarging the original concept of the LEPRICON adjustment procedure $(1,2,3)$ to include methods for obtaining á priori values of calculated surveillance dosimeter activities and pressure vessel fluence rates in PWR systems $(4,5)$, as well as in applying some of these methods to the analysis of experiments performed in reactor-like environments $(6,7,8)$, new and improved techniques have been developed to handie various aspects of the general transport process.

\section{ABSOLUTE NEUTRON SOURCE DJSTRIBUTIUNS}

For analysis of PWR surveillance dosimetry, it has been found adequate in the analys is of the Arkansas Nuclear One-Unit I reactor (ANO-1) to use in-core assembly power data determined from self-powered neutron detectors (SPND) in conjunction with diffusion theory calculations that provide reasonable intra-assembly power disiributions for the peripneral assemblies. Thus,

$$
P(x, y, z, m)=P(z, m)\left[p(x, y, m) / \int_{V_{m}} p(x, y, m) d V\right] .
$$

where $P(x, y, z, m)$ is the power spatial distribution for peripheral assembly $m, P(z, m)$ is the axial power distribution as measured by SPND's in assembly $m$, and $p(x, y, m)$ is the diffusion theory calculated horizontal midplane power distribution for assembly $\mathrm{m}$. By defining $\mathrm{Eq}$. (1) to hold over some coarse ti.ne interval $\Delta t_{j}$ and multiplying it by $F_{j}\left(\Delta t_{j}\right)$, the "instantaneous" fraction of the SPND power of duration $\Delta t_{i}, \Delta t_{j} \varepsilon \Delta t_{,}$, which is extracted from the power history and reflects power level swings during operation, a suitable approximation to the peripheral power distribution as a function of time may be written as

$$
P\left(x, y, z, m_{,} \Delta t_{j}\right)=F_{j}\left(\Delta t_{j}\right) P_{j}\left(z, m, \Delta t_{j}\right)\left[p_{j}(x, y, m) / \int_{V_{m}} P_{j}(x, y, m) d V\right] \text {. }
$$

Throughout cycles 4 and 5 of this reactor, which have been the only ones analyzed so far, the virtually time-independent pin-by-pin peripheral assembly distributions were such that the core leakage averaged about 15-20\% less than that from a flat distribution normalized to che same assembly powers. Thus, neglecting the fall-off in pin-by-pin power with increasing radius for the peripheral assemblies would result in typical overestimates of the order of $20 \%$ in calculated pressure vessel fluences. The conversion factor relating neutron production rate to the powar expressed in Eq. (2) is burn-up dependent because of different values for $239 \mathrm{Pu}$ and $235 \mathrm{U}$. The fission spectrum is also somewhat different for these two isotopes. Both of these effects tend to increase the high-energy fluence with time over that obtained if 


\section{RECENT PROGRESS IN LWR-PV CALCULATIONAL METHODOLOGY}

they were neglected, but their combined effect is probably significant ( $>5 \%)$ only for low leakage cores in which partially burned fuel is used in the peripheral assemblies.

\section{EFFECTS OF THE FINITE CORE HEIGHT}

These effects and their treatment have been discussed elsewhere $(6,7,8,9)$ for near-midpiane locations, but only corrections for PWR reactor cavity positions probably need to be considered. For the PCA and PSF experiments, however, even calculations at surveillance and pressure vessel midplane locations need to be corrected, since the core height is relatively small compared to detector distances from the core. For axial locations further than about one-fourth of the core height from the horizontal midplane, the simple fluence rate synthesis procedure given below begins to break down. The procedure is based on combining results from three transport calculations. For PWR applications,

$$
\phi_{g}(R, \theta, Z)=\phi_{g}(R, \theta) \phi_{g}(R, Z) / \phi_{g}(R) \text {. }
$$

where

$$
\begin{aligned}
& \phi_{g}(R, \theta) \text { is the solution using } S(R, \theta)=\int_{-\infty}^{\infty} S(R, \theta, Z) d Z, \\
& \phi_{g}(R, Z) \text { is the solution using } S(R, Z)=\int_{0}^{2 \pi} S(R, \theta, Z) R d \theta,
\end{aligned}
$$

and

$$
\phi_{g}(R) \text { is the solution using } S(R)=\int_{0}^{2 \pi} R d \theta \int_{-\infty}^{\infty} S(R, \theta, Z) d Z \text {. }
$$

In applications to AN0-1, and presumably many other reactors, the ratio $\phi_{g}(R, Z) / \phi_{g}(R)$ was assumed to be independent of the source distribution because all axial loadings were virtually identical.

\section{EFFECTS OF TIME-DEPENDENT SPATIAL SOURCE DISTRIBUTIONS}

Source spatial distributions in general are functions of time, and both intracycle and intercycle variations may be important as they can affect pressure vessel fluence. A method based on the concept of the adjoint function has been developed and simplified which allows ore to obtain not only surveillance activities at the end of irradiation and pressure vessel fluences for any arbitrary source distribution without the time and expense of performing new transport calculations each time, but also to investigate effects on pressure vessel fluence alone from different core loadings and fuel shuffling schemes. 


\section{RECENT PROGRESS IN LWR-PV CALCULATIONAL METHODOLOGY}

Turning our attention first to calculating the dosimeter saturated activities $\operatorname{RR}^{d}(t)$,

$$
\cdot R R^{d}(t)=\int_{\text {detector }} d \bar{r} \int_{0}^{\infty} \phi(E, r, t) \sigma^{d}(E) u^{\prime} E=\iint_{\text {core }} d \bar{r} \int_{0}^{\infty} \phi_{d}^{\star}(E, \bar{r}) S(E, \bar{r}, t) d E,
$$

where $\phi$ is the "forward" calculated fluence rate, $\phi_{d}^{*}$ is the adjoint fluence rate using $\sigma d$, the reaction cross section for dosimeter $d$, as the adjoint source, and $S$ is the core source.

$$
\text { Since } S(E, \vec{r}, t ;=x(E) S(\vec{r}, t) \text {, }
$$

where $x$ is a normalized fission spectrum,

$$
R^{d}(t)=\int_{\text {core }} S(\bar{r}, t) d \bar{r} \int_{0}^{\infty} x(E) \phi_{d}^{*}(E, \bar{r}) d E \text {. }
$$

We may rewrite Eq. (9) as

$$
\operatorname{RR}^{d}(t)=\sum_{k=1}^{8} \int_{0}^{\infty} x(E) d E \int_{x c t a n t} \phi_{d}^{*}(k, \bar{r}, E) S(k, \bar{r}, t) d \bar{r},
$$

where $k$ denotes a given octant of the core.

Most_fuel loading patterns exhibit the octal symmetry property $S(k, \bar{r}, t)=S(\bar{r}, t)$ for all $k$, leading to

$$
\operatorname{RR}^{d}(t)=\sum_{k=1}^{8} \int_{0}^{\infty} x(E) d E \int_{\text {octant }} \phi_{d}^{*}(k, \bar{r}, E) S(\bar{r}, t) d \bar{r} .
$$

Equation (11), requiring a model of the complete core, may be greatly simplified if the adjoint function is calculated modeling only the nearest octant of the core together with imposing a perfectly reflecting boundary condition on the two limiting rays of the octant (see Fig. 1). Since, by symmetry, fig. 1 is equivalent to no reflective boundary condition and eight symmetrically placed sources about the core (broken crosses in Fig. 1), one has, in terms of the reflected adjoint function $\phi_{d, R}^{*}$,

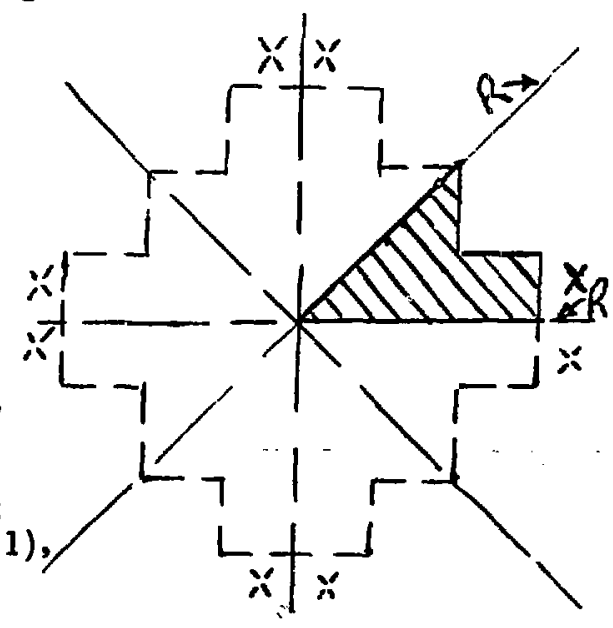

Fig. 1. Rèflected Geometry Using One Octant of the Core 
RECENT PROGRESS IN LWR-PV CALCULATIONAL METHODOLOGY

$$
\int_{0}^{\infty} x(E) d E \int_{\text {core }} \phi_{d, R}^{*}(\bar{r}, E) S(\bar{r}, t) d \bar{r}=8 R R^{d}(t),
$$

and since all octants are identical,

$$
\int_{0}^{\infty} x(E) d E \int_{\text {octant }} \phi_{d, R}^{*}(\bar{r}, E) S(\bar{r}, t) d \bar{r}=R R^{d}(t) .
$$

Thus, subtracting Eq. (13) from Eq. (11) and interchanging the order of octant summing and integration,

$$
\int_{0}^{\infty} x(E) d E \int_{\text {octant }}\left\{\sum_{k=1}^{8} \phi_{d}^{*}(k, \bar{r}, E)-\phi_{d, R}^{*}(\bar{r}, E)\right\} S(\bar{r}, t) d \bar{r}=0,
$$

and since $S(\bar{r}, t)$, is arbitrary,

$$
\sum_{k=1}^{8} \phi_{d}^{*}(k, \bar{r}, E) \equiv \phi_{d, R}^{*}(\bar{r}, E) \text {. }
$$

Thus, al though the adjoint geometry is asymnetric, the adjoint function readily calculated with reflective boundary conditions in octal geometry is the correct solution if the core loading is octally symmetric. The quantity $x(E) \phi_{j}^{*}(\bar{r}, E)$ is the Green's function for the response function $\sigma^{d}(E)$ and a particular location of the detector.

Figure 2 illustrates the behavior of the ratio of the Green's functions of ${ }^{237} \mathrm{~Np}(n, f)$ relative to ${ }^{63} \mathrm{Cu}(n, \alpha)$ for surveillance dosimeters located near the region of peak pressure vessel fluence in ANO-1. The five shaded quarter assemblies represent regions of greatest contribution to the dosimeter activities, and the near constancy of this ratio, which involves two completely different energy intervals, is to be observed. Similar conclusions can be inferred from the distributions in Fig. 3, where the dosimeters are located in the ANO-1 reactor cavity. One may conclude from Figs. 2 and 3 that the similar spatial dependence of the two Green's functions over the contributing part of the core for two such disparate response functions implies, by Eq. (13), the inde.pendence of the relative reaction rates with source distribution. Hence the relative fluence rates at a given surveillance or pressure vessel location also tend to be independent of spatial source distribution. Only the intensity of the total fluence rate is affected by the source distribution; the spectrum at a given location remains virtually independent of the source. 
RECENT PROGRESS IN LWR-PV CÂLCUIATIONAL METHODOLOGY

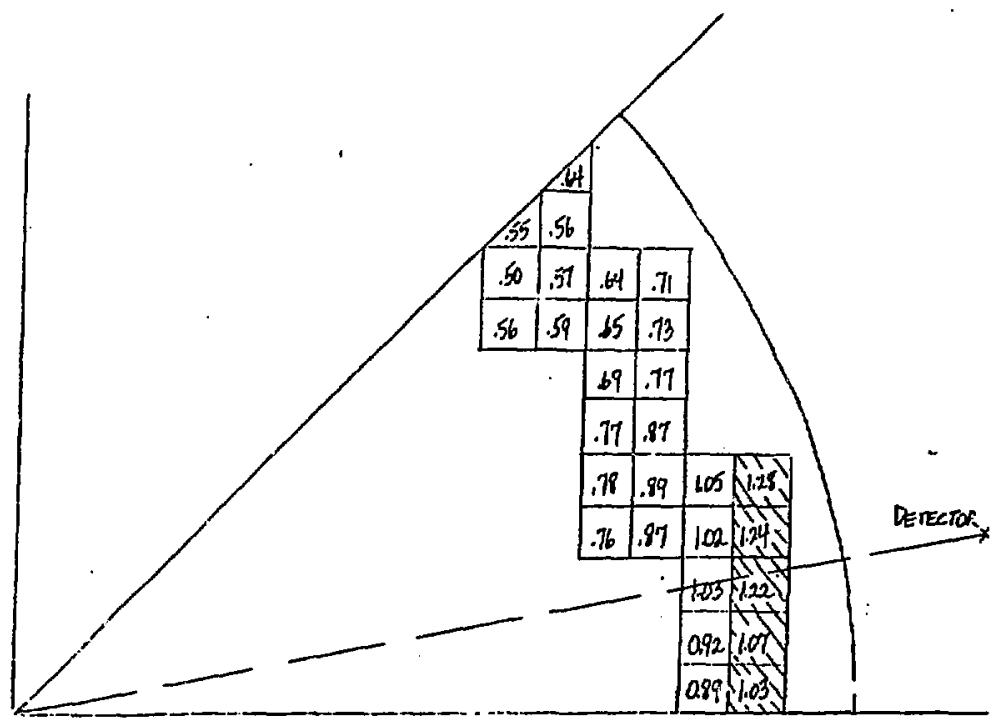

Fig. 2. Ratio of Weighted Source Importances of Quarter Periphera? Core Assemblies Summed Over All Octants, $237_{\mathrm{Np}}(n, f) /$ ${ }^{63} \mathrm{Cu}(n, \alpha)$, in Units of $10^{3}$. Detector at Surveiliance Lr'. ${ }^{2}$, in Downcomer.

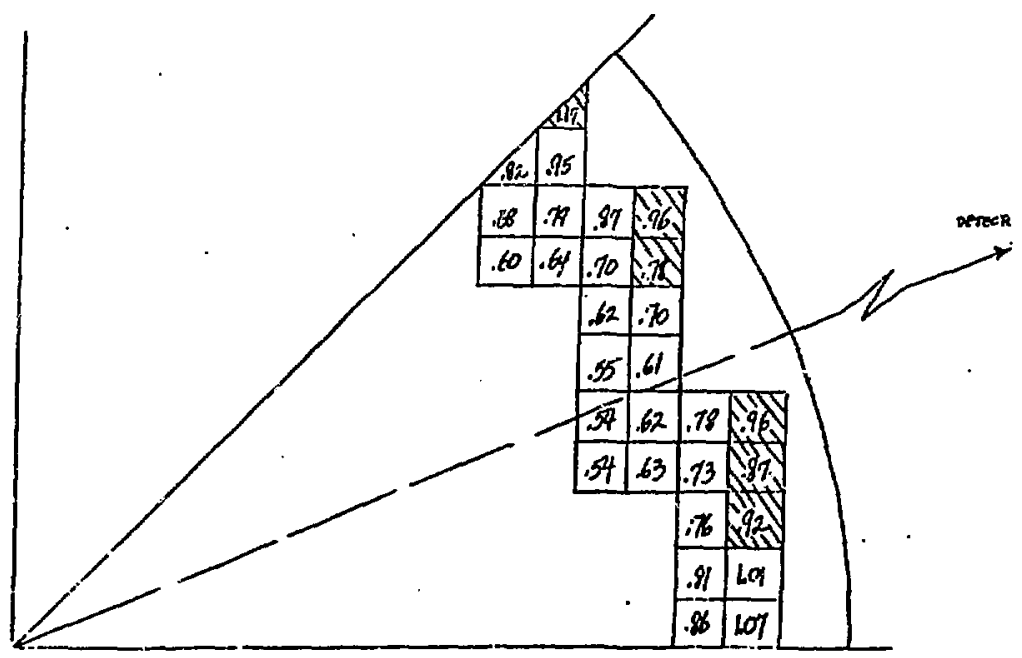

Fig. 3. Ratio of Weighted Source Importances of Quarter Peripheral Core Assemblies Summed Over All Octants, ${ }^{23} \mathrm{~Np}(n, f) /$ ${ }^{63} \mathrm{Cu}(n, \alpha)$, in Units of $10^{4}$. Detector in Reactor Ca:ity. 


\section{RECENT PROGRESS IN LWR -PV CALCULATIONAL METHOOULOGY}

The constancy of the spectrum allows one to calculate all the losimeter activities for a new source distribution by using only the one adjoint function and scaling the original dosimeter activities by the ratio of the new to the old activities obtained for the particular dosimeter whose response cross section was used in calculating the adjoint function. Trus the saturated activities $R_{R} d(t)$ and $R R^{d}\left(t_{0}\right)$ calculated from Eq. (13) using the sources $S(\bar{r}, t)$ and $S\left(\bar{r}, t_{0}\right)$, respectively may be used in conjunction with the activities $R R d\left(t_{o}\right)$ obtained from a forward calculation performed earlier using the, reference source $S\left(\bar{r}, t_{0}\right)$ to provide new saturated activities $R R d(t)$ for all the dosimeters:

$$
R R^{d^{\prime}}(t)=\left\{\left[R R^{d}(t)\right]_{\text {adjoint }} /\left[R R^{d}\left(t_{0}\right)\right]_{\text {adjoint }}\right\}\left[R R^{d^{\prime}}\left(t_{0}\right)\right]_{\text {forward }}
$$

As an illustration, we have calculated in the forward mode the activities in the ANO-1 cavity for each of two source distributions - one flat and the other modified by a pin-by-pin diffusion theory calculation. Taking the flat distribution as the new distribution and the pin-by-pin distribution as the original one, the new activities were calculated as well by scaling the original ones using each of two adjoint functions in Eq. (16). The results appear in Table 1.

Table 1. Comparison of Forward with Adjoint Scaled Saturated Activities in the ANO-1 Cavity for a

Flat Intra-Assembly Source Distribution

\begin{tabular}{lcccccc}
\hline Dosimeter & $\begin{array}{c}\text { Using } \\
63 \mathrm{Cu}(n, \alpha) \\
\text { Adjoint }\end{array}$ & $\begin{array}{c}\text { Using } \\
237_{\mathrm{Np}(n, f)} \\
\text { Adjoint }\end{array}$ & Forward & \multicolumn{2}{c}{ Discrepancy } \\
\hline${ }^{63} \mathrm{Cu}(n, \alpha)^{60} \mathrm{Co}$ & $6.43-17^{\dagger}$ & $6.74-17$ & $6.43-17$ & $0.0 \%$ & $4.8 \%$ \\
${ }^{46} \mathrm{Ti}(n, p){ }^{46} \mathrm{SC}$ & $8.85-16$ & $9.29-16$ & $8.92-16$ & $1.0 \%$ & $4.1 \%$ \\
${ }^{54} \mathrm{Fe}(n, p){ }^{54} \mathrm{Mn}$ & $4.86-15$ & $5.10-15$ & $4.97-15$ & $2.3 \%$ & $2.6 \%$ \\
${ }^{58} 8_{\mathrm{Ni}(n, p)}{ }^{58} \mathrm{Co}$ & $6.74-15$ & $7.07-15$ & $6.90-15$ & $2.4 \%$ & $2.5 \%$ \\
${ }^{238} \mathrm{U}(n, f) F . P$. & $2.83-14$ & $2.98-14$ & $2.93-14$ & $3.5 \%$ & $1.7 \%$ \\
${ }^{237} \mathrm{~Np}(n, f) F . P$. & $4.92-13$ & $5.17-13$ & $5.17-13$ & $5.1 \%$ & $0.0 \%$ \\
\hline
\end{tabular}

TRead $6.43 \times 10^{-17}$ reactions per second per aton, etc.

Table 1 indicates about the same error is incurred using either extreme adjoint function, but that using an intermediate one calculated from either the ${ }^{54} \mathrm{Fe}(n, p)$ or the ${ }^{58} \mathrm{Ni}(n, p)$ cross section should result in no worse than about a $2.5 \%$ error.

Even though the spectrum changes with detector location throughout the pressure vessel for a given source, no changes in these relative spectra are induced by changes in the source; i.e., these spectra are determined strictly by the neutron transport 


\section{RECENT PROGRESS IN LWR-PV CALCULATIONAL METHODOLOGY}

properties of the downcomer and pressure vessel. Hence, one can use Eq. (16) as well to use scaling factors at one location to obtain activities at another, as is illustrated in Table 2.

Table 2. Comparison of Forward with Downcomer Adjoint Scaled Saturated Activities in the ANO-1 Cavity for a Flat Intra-Assembly Source Distribution

\begin{tabular}{lcccccc}
\hline Dosimeter & $\begin{array}{c}\text { Using } \\
63 \mathrm{Cu}(n, \alpha) \\
\text { Adjoint }\end{array}$ & $\begin{array}{c}\text { Using } \\
237_{\mathrm{Np}(n, f)} \\
\text { Adjoint }\end{array}$ & Forward & \multicolumn{2}{c}{ Discrepancy } \\
\hline${ }^{63} \mathrm{Cu}(n, \alpha)^{60} \mathrm{Co}$ & $6.18-17^{\ddagger}$ & $6.46-17$ & $6.11-17$ & $1.1 \%$ & $5.8 \%$ \\
${ }^{46} \mathrm{Ti}(n, p)^{46} \mathrm{Sc}$ & $8.48-16$ & $8.87-16$ & $8.45-16$ & $0.4 \%$ & $4.9 \%$ \\
$\left.{ }^{54} \mathrm{Fe}(n, p)\right)^{54} \mathrm{Mn}$ & $4.67-15$ & $4.88-15$ & $4.73-15$ & $1.2 \%$ & $3.3 \%$ \\
${ }^{58} \mathrm{Ni}(n, p){ }^{58} \mathrm{Co}$ & $6.47-15$ & $6.76-15$ & $6.57-15$ & $1.6 \%$ & $2.9 \%$ \\
${ }^{238} \mathrm{U}(n, f) F . P$. & $2.71-14$ & $2.84-14$ & $2.80-14$ & $3.1 \%$ & $1.5 \%$ \\
${ }^{237_{\mathrm{Np}}(n, f) F . P .}$ & $4.77-13$ & $4.98-13$ & $4.96-13$ & $4.1 \%$ & $0.4 \%$ \\
\hline
\end{tabular}

${ }^{*}(\text { RRd })_{\text {FLAT,CAVITY }}=\frac{\left\{(R R C U)_{\text {FLAT, SURV }}\right\}_{\text {AOJUINT }}}{\left\{\left(R R^{C U}\right)_{P I N-B Y-P I N, \text { SURV }}\right\}_{\text {ADJOINT }}}$.

- $\left\{\left(\text { RRd }^{d}\right) P I N-B Y-P I N, \text { CAVITY }\right\}_{\text {FURHARD }}$

tsimilar to above with $R R^{N p}$ replacing $R R^{C}$.

FRead $6.18 \times 10^{-17}$ reactions per second per atom, etc.

Combining Eqs. (2-6) with Eqs. (13) and (16) and decaying the resultant saturated activity to the end of irradiation yields the following expression for the activity when the power spatia? distribution is a function of time:

$$
\begin{aligned}
& A^{d^{\prime}}(T)=e^{-\lambda d^{-} T}\left(\frac{R R^{d^{*}}}{R R^{d}}\right) \cdot \\
& \cdot \sum_{j=1}^{J} C_{j} \sum_{g=1}^{G} x_{g, j} \int_{\text {octant }}^{\int P_{j}(r) \phi_{g, d, R}^{\star}}(r) \overline{d r} \sum_{j=1}^{I(j)} F_{i}\left[1-e^{-\lambda d^{-}\left(t_{j+1}-t_{j}\right)}\right] e^{\lambda d^{-t_{i+1}}},
\end{aligned}
$$

where $A^{d^{\prime}}(T)=$ Activity of dosimeter $d^{-}$in dps/atom at end of irradiation,

$\lambda_{\mathrm{d}^{*}}=$ Decay constant of dosimeter $d^{\prime}$ in reciprocal days

$$
\begin{aligned}
\mathrm{RRd}^{-} & =\text {Irradiation period in days, } \\
& =\text { Saturated activity of dosimeter } d^{-} \text {calculated in }
\end{aligned}
$$
the forward mode using the fluence rate synthesis procedure expressed by $\mathrm{Eq}$. (3) with some reference

$R^{d}=$ Saturated activity vi dosimeter d calculated in the adjoint mode in $R-\theta$ geometry using the same reference source as above, 
RECENT PRUGRESS IN LWR-PV CALCULATIONAL METHODOLOGY

$$
\begin{aligned}
& J=\text { Number of distinct relative spatial distributions } \\
& \text { used over } \mathrm{T} \text {, } \\
& c_{j}=\text { Conversion factor relating neutron source and } \\
& \text { assembly power in units of neuts/sec per MW, } \\
& x_{g, j}=\text { Relative number of neutrons in group } g \text { produced per } \\
& \phi_{g, d, R}^{*}=\text { Adjoint flux in group } g \text { ( } i . e ., g=1 \text { corresponds to } \\
& \text { lowest energy group) calculated in an adjoint } \\
& \text { octally reflected } R-\theta \text { run using the response of } \\
& \text { dosimeter } d \text {, in disintegrations per atom per } \\
& \text { neutron per } \mathrm{cm}^{3} \text {, } \\
& P_{j}=\text { The } x, y \text { power density distribution in the } \\
& \text { peripheral core integrated over } z \text { based on SPNO } \\
& \text { data and supplemented by diffusion theory pin-by- } \\
& \text { pin calculations, in } M W \text { per } \mathrm{cm}^{3} \text {, } \\
& I(j)=\text { Number of subintervals describing "instantaneous" } \\
& \text { total power history for each SPND interval } j \text {, } \\
& F_{i}=\text { Fraction of total SPND power in fine time interval } \\
& i \text { due to "instantaneous" power level changes, } \\
& t_{i}, t_{j+1}=\begin{array}{c}
\text { Beginning and end of time subinterval } i \text { relative to } \\
\text { beginning of irradiation, in days. }
\end{array}
\end{aligned}
$$

Although they will not be detailed here, similar considerations based on adjoint functions for the various group fluence rates in the pressure vessel can lead to expressions for the group fluences arising from time dependent spatia: source distributions. In agreement with conclusions dedused from the behavior of the various reaction rates, the group fluence rates were found to scale with predictable accuracies ranging from two to five percent when the scaling takes into account, as it should, the dependence of the group fluence rates on the source fission spectrum as well $(10)$.

\section{REFERENCES}

1. R. E. Maerker, J. Jo Wagschal and B. L. Broadhead, Development and Demonstration of an Advanced Methodology for LWR Dosimetry Applications, EPRI NP-2188, Interim Report (1981).

2. R. E. Maerker, M. L. Wi iliams, B. L. Broadhead, J. J. Wagschal and C. Y. Fu, Revision and Extension of the Database in the LEPRICON Dosimetry Methodology, Second Interim Report, to be published as an EPRI report (1984).

3. J. J. Wagschal, R. E. Maerker and B. L. Broadhead, "Surveillance Dosimetry: Achievements and Disappointments," Proc. Fourth ASTM-EURATOM Symposium on Reactor Dosimetry, Vol. 1, NUREG/CP-0029, CONF-82032/V1, NBS (1982). 


\section{RECENT PROGRESS IN LWR-PV CALCULATIONAL METHODOLOGY}

4. R. E. Maerker, B. L. Broadhead, B. A. Worley, M. L. Williams and J. J. Wagschal, Application of the LEPRICON System to the ANO-1 Reactor, Third Interim Report, to be pubTished as an EPRI Report (1985).

5. J. J. Wagschal, R. E. Maerker, B. L. Broadhead and M. L. Williams, "Infolded ANO-1 Fluxes Using the LEPRICCN Methodology," Proceedings this Conference.

6. W. N. McElroy, (Ed.), LWR Pressure Vessel Surveiliance Dosimetry Improvement Program: PCA Experiments and BTind Test, NUREG/CR-1861, HEDL-TME 80-87, R5, Hanford Engineering Development Laboratory (1981).

7. R. E. Maerker and B. A. Worley, "Calculated Spectral Fluences and Dosimetry Activities for the Metallurgical Blind Test Irradiations at the ORR-PSF," Proceedings this Conference.

8. R. E. Maerker and B. A. Worley, Activity and Fluence Calculations for the Startup and Two-Year Irradiation Experiments Performed at the Poolside Facility, NUREG/CR-3886, ORNL/TM-9265 (1984).

9. R. E. Maerker and M. L. Williams, "Calculations of the Westinghouse Perturbation Experiment at the Poolside Facility," Proc. Fourth ASTM-EURATOM jymposium on Reactor Dosimetry, Vol. I, NUREG/CP-0029, CONF-820321/V1, NBS (1982).

10. B. L. Broadhead and R. E. Maerker, "Sensitivities of the Flux Spectruiii in the Cavity of a PWR to Variations in the Core Source Distribution, " Trans. Am. Nucl. Soc. 46, 659 (1984).

\section{DISCLAIMER}

\footnotetext{
This report was prepared as an account of work sponsored by an agency of the United States Government. Neither the United States Government nor any agency thereof, nor any of their employees, makes any warranty, express or implied, or ussumes any legal liability or responsibility for the accuracy, completeness, or usefulness of any information, apparatus, product, or process disclosed, or represents that its use would not infringe privately owned rights. Reference herein to any specific commercial product, process, or service by trade name, trademark, manufacturer, or otherwise does not necessarily constitute or imply its endorsement, recommendation, or favoring by the United States Government or any agency thereof. The views and opinions of authors expressed herein do not necessarily state or reflect those of the United States Government or any agency thereor.
} 